\title{
Why isn't 'time out' being implemented? An exploratory study
}

Brigid M Gillespie, Wendy Chaboyer, Marianne Wallis, et al.

Qual Saf Health Care 2010 19: 103-106 originally published online March 8, 2010

doi: 10.1136/qshc.2008.030593

Updated information and services can be found at:

http://qshc.bmj.com/content/19/2/103.full.html

These include:

References This article cites 10 articles, 3 of which can be accessed free at: http://qshc.bmj.com/content/19/2/103.full.html\#ref-list-1

Email alerting Receive free email alerts when new articles cite this article. Sign up in the service box at the top right corner of the online article.

\section{Notes}

To order reprints of this article go to:

http://qshc.bmj.com/cgi/reprintform

To subscribe to Quality and Safety in Health Care go to:

http://qshc.bmj.com/subscriptions 


\title{
Why isn't 'time out' being implemented? An exploratory study
}

\author{
Brigid M Gillespie, ${ }^{1}$ Wendy Chaboyer, ${ }^{2}$ Marianne Wallis, ${ }^{3}$ Clare Fenwick ${ }^{1}$
}

${ }^{1}$ Research Centre for Clinical \& Community Practice Innovation \& School of Nursing \& Midwifery, Griffith University, Gold Coast, Queensland, Australia ${ }^{2}$ Research Centre for Clinical \& Community Practice Innovation Griffith University, Queensland, Australia

${ }^{3}$ Research Centre for Clinical \& Community Practice Innovation \& Gold Coast Health Service District, Griffith University, Gold Coast Campus Queensland, Australia

\section{Correspondence to}

Dr Brigid M Gillespie, Research Centre for Clinical \& Community Practice Innovation \& School of Nursing \& Midwifery, Griffith University, Gold Coast, Queensland, Australia; b.gillespie@griffith.edu.au

Accepted 20 May 2009

\section{ABSTRACT}

Background While there has been much discussion extolling the virtues of using 'time out' as a means of preventing the potential for sentinel events, to date there has been little examination of the issues that impact on clinicians' uptake of 'time out' in operating-room settings. Aim This study sought to methodically identify implementation and practice issues associated with the introduction and ongoing use of a 'time out' protocol in a large healthcare organisation.

Methods Sixteen participants were interviewed and included surgeons, anaesthetists, nurse managers and nurses who worked at the clinical interface. Textual data were analysed using a grounded theory approach, identifying subcategories to illustrate causal relationships to the category.

Results The category 'ambivalent compliance with "time out"' was the central idea that was recognised by events and behaviours that surrounded the introduction of 'time out.' Subcategories included haphazard implementation of time out, hierarchical team culture and tribal affiliations of members, and clashing clinical priorities make it difficult to incorporate 'time out' into practice, and led to 'ambivalent compliance.'

Conclusion There is little doubt that using a 'time out' protocol in the operating room allows team members to share explicit confirmation of safety-related details.

However, when introducing patient safety initiatives into practice, recognising compliance issues is an important first step towards identifying ways in which to address them.

Approximately 234 million operations are performed around the world every year. ${ }^{1}$ The delivery of safe patient care during the perioperative phase is crucial to minimise the risk of adverse events. Adverse events during surgical procedures occur in $3-22 \%$ of patients, and many of these are entirely preventable. ${ }^{2}$ Communication failures are recognised as the most prevalent factor underlying adverse events. ${ }^{3}$ In Australia, about $50 \%$ of adverse events in Australian hospitals occur as a result of communication failures between healthcare professionals, in particular, nurses and doctors. ${ }^{4}$ The consequences of communication failures in surgery are evident in sentinel events that culminate in wrong site/side surgery. Recent research has shown that in the OR, information may be inacurate or too late, or does not reach the individuals who need to know, leaving issues unresolved until they become critical. ${ }^{5}$ In response to this increasing problem, there has been strong international endorsement of prebriefing strategies such as using 'time out' in the OR. ${ }^{7}$

'Time out' briefings are intended to establish a forum for open and interactive communication; emphasise the importance of questions and critique; and cover pertinent safety and operational issues. ${ }^{8}$ 'Time out' involves a sequenced protocol, using a checklist format that allows team members to share their knowledge of the case and to resolve knowledge gaps in relation to patient and procedural information (ie, identify patient, consent, mark site, final check). Using a checklist to systematically brief all team members (ie, surgeon, anaesthetist, nurse and technician) ensures that nothing is forgotten and takes approximately 1-5 min prior to anaesthetic induction. US researchers 89 found that the 'time out' protocol increased explicit confirmation of safety-related details such as patients' allergies and the availability of blood products by $50 \%$. Additionally, 'time out' improved teamwork and nursing retention and prompted earlier reporting of equipment issues and wrong site/wrong surgical procedures, ultimately resulting in fewer clinical incidents. ${ }^{9-11}$

Nevertheless, clinicians' willingness to change behaviour may influence the successful introduction and subsequent uptake of structured communication strategies, such as 'time out.' The literature is replete with discussion of the utility of 'time out' as a means of averting the potential for sentinel events; however, there has been little exploration of the issues that impact on end-user uptake of 'time out' in OR settings. Additionally, implications associated with the introduction and sustained use of 'time out' in clinical practice in large healthcare organisations have not been examined. Findings reported in this paper were part of a larger study which examined teamwork and communication practices in the OR. This study sought to systematically identify implementation and practice issues associated with the introduction and ongoing use of a 'time out' protocol.

\section{METHODS \\ Research setting}

The research setting was an OR department in a large metropolitan hospital in southern Queensland, Australia. Following ethics approval from the hospital and university, consent was obtained from a purposive sample of doctors, nurse managers and clinical nurses who practised across various surgical specialities which included general, ophthalmology, vascular, gynaecology, orthopaedic, urology and neurosurgery.

\section{Data collection}

Participants were selected purposively to conform to maximum variation sampling ${ }^{12}$ to ensure inclusion of all key stakeholders, and the consequent representativeness of the sample. All interview 
participants were current employees of the organisation during implementation of 'timeout;' hence, the sample was homogenous in this respect. Sample heterogeneity was evident in the diversity of relationships individuals had to 'timeout.' Individual and groups interviews were conducted with physicians, nurse managers and OR nurses who worked at the clinical interface. Eight interviews were conducted with a total of 16 participants. Of these, four individual interviews were conducted with physicians, while four group interviews were conducted with nurse managers and clinical nurses who worked across various surgical subspecialities. Semistructured interviews using a collation of issues based around 'time out' and communication explored wider organisational and end-user perspectives of 'time out.' Interviews lasted 45-60 min and were audiotaped. Data saturation was evident when no new information was forthcoming.

\section{Data analysis}

Data were analysed using inductive and deductive approaches underpinned by grounded theory methods as described by Strauss and Corbin. ${ }^{13}$ Textual data were analysed to illustrate causal relationships between subcategories and the overarching category. ${ }^{13}$ The category 'ambivalent compliance with timeout' emerged inductively. This category is described in connection with the intervening conditions that give rise to it; contextual conditions that relate to situations in which the category is embedded; the actions/interactions by which it is managed; and the consequences of those actions. ${ }^{13}$ The subcategories, which acted as causal conditions, were analysed deductively to examine the features (ie, intervening conditions, contextual conditions, actions/interactions and their consequences) of the category, 'ambivalent compliance,' that emerged inductively.

\section{RESULTS}

In total, 16 participants were interviewed, including four physicians, three nurse managers and nine registered nurses. Analysis of the data identified the category "ambivalent compliance with "time out".' Ambivalent compliance was expressed in the diverse opinions and behaviours of participants to the introduction of the 'time out' policy. While 'time out' was compulsory, support for, and participation in, this activity varied among physicians in particular. Compliance was influenced by the ways in which the organisation introduced the change in policy, participants' willingness and response to this change and the actions that occurred as a result. Subcategories included haphazard implementation of time out, hierarchical team culture and tribal affiliations of members, and clashing clinical priorities make it difficult to incorporate 'time out' into practice, and led to 'ambivalent compliance.' Table 1 details the connection between these three subcategories and the category, 'ambivalent compliance' in relation to intervening conditions, contextual conditions, actions and interactions, and their consequences.

\section{Ambivalent compliance with 'time out'}

The first subcategory, haphazard implementation of time out, was potentiated by intervening conditions such as the organisation's bureaucratic approach and limited deployment of resources needed to support the introduction of a new clinical protocol. Contextual conditions, such as a lack of clarity and agreement with protocol specifics, and inadequate executive leadership primarily, resulted in reduced ownership and acceptance of the protocol by physicians. 'Time out' was difficult to 'sell' to physicians, because they had received little education or inservice about it; moreover, it was introduced prior to consultation with senior physicians. It was challenging for senior physicians whose role it was to enforce the protocol among professional peers, as they did not necessarily agree with it, albeit this protocol was endorsed by the College of Surgeons. In an attempt to remedy this, responsibility for protocol implementation was devolved to senior nurse managers. Consequently, while the introduction of time out conceivably had the greatest impact on physicians' practice, its implementation was neither initiated nor whole-heartedly supported by them.

Hierarchical team culture and tribal affiliations of members, the second subcategory, was accentuated by intervening conditions such as departmental culture, uniprofessional identification and team history. Contextual conditions, such as team instability and reduced cohesion, lack of leadership and physician resistance, created contention over when and by whom the 'time out' check should be completed. In order to resolve these

Table 1 Subcategories that influenced 'ambivalent compliance with time out'

\begin{tabular}{|c|c|c|c|c|c|}
\hline Subcategory & Category & Intervening conditions & Contextual conditions & Actions/interactions & Consequences \\
\hline $\begin{array}{l}\text { Haphazard implementation } \\
\text { of 'time out' }\end{array}$ & $\begin{array}{l}\text { Ambivalent compliance with } \\
\text { 'time out' }\end{array}$ & $\begin{array}{l}\text { - Organisational } \\
\text { culture } \\
\text { Limited resources/ } \\
\text { infrastructure }\end{array}$ & $\begin{array}{l}\text { Funding and resource } \\
\text { limitations } \\
\text { Policy ambiguous } \\
\text { - Limited executive } \\
\text { leadership } \\
\text { Limited education of } \\
\text { physicians } \\
\text { Lack of consultation with } \\
\text { key enablers }\end{array}$ & $\begin{array}{l}\text { Implementation of 'time } \\
\text { out' driven by nurse } \\
\text { managers } \\
\text { Divergent interpretation of } \\
\text { 'time out' policy by } \\
\text { key stakeholders }\end{array}$ & $\begin{array}{l}\text { 'Time out' initiative not } \\
\text { supported by all physician } \\
\text { stakeholders } \\
\text { Interprofessional disso- } \\
\text { nance } \\
\text { Not implemented by physi- } \\
\text { cians }\end{array}$ \\
\hline $\begin{array}{l}\text { Hierarchical team culture and } \\
\text { tribal affiliations of members }\end{array}$ & & $\begin{array}{l}\text { Departmental } \\
\text { culture } \\
\text { - Uniprofessional } \\
\text { identification } \\
\text { - Team history }\end{array}$ & $\begin{array}{l}\text { Team instability \& lack of } \\
\text { familiarity } \\
\text { Reduced team cohesion } \\
\text { Rack of clinical leadership } \\
\text { - Physicians not available } \\
\text { for 'time out' } \\
\text { - Physician resistance }\end{array}$ & $\begin{array}{l}\text { Ineffective team } \\
\text { communication } \\
\text { Inconsistent use of } \\
\text { existing guidelines } \\
\text { 'Time out' initiated and } \\
\text { led by nursing staff }\end{array}$ & $\begin{array}{l}\text { Vital information not } \\
\text { passed on } \\
\text { 'Silo' mentality } \\
\text { - Interprofessional disso- } \\
\text { nance and conflict } \\
\text { 'Time out' used } \\
\text { inconsistently } \\
\text { - Patient safety compro- } \\
\text { mised }\end{array}$ \\
\hline $\begin{array}{l}\text { Clashing clinical priorities } \\
\text { make it difficult to incorporate } \\
\text { 'time out' into practice }\end{array}$ & & $\begin{array}{l}\text { Departmental } \\
\text { culture } \\
\text { Amount of clinical } \\
\text { experience of team } \\
\text { members }\end{array}$ & $\begin{array}{l}\text { Lack of clinical experience } \\
\text { Increased workloads } \\
\text { Availability of staff } \\
\text { Conflicting priorities } \\
\text { - Staff shortages }\end{array}$ & $\begin{array}{l}\text { Inconsistent use of } \\
\text { existing guidelines } \\
\text { Time out protocol not } \\
\text { always performed }\end{array}$ & $\begin{array}{l}\text { 'Time out' used } \\
\text { inconsistently } \\
\text { Patient safety compro- } \\
\text { mised } \\
\text { 'Time out' initiated and led } \\
\text { by nursing staff } \\
\text { Nursing staff stress }\end{array}$ \\
\hline
\end{tabular}


Table 2 Subcategory, descriptions, and examples of verbatim

\begin{tabular}{|c|c|c|}
\hline Subcategory & Description & Illustrative examples of verbatim \\
\hline $\begin{array}{l}\text { Haphazard } \\
\text { implementation of } \\
\text { 'time out' }\end{array}$ & $\begin{array}{l}\text { Described participants' perceptions of the } \\
\text { ways in which the 'time out' protocol } \\
\text { was introduced and rolled out within the } \\
\text { organisation }\end{array}$ & $\begin{array}{l}\text { When it [timeout] was brought into this organisation, it was a dump and run....They needed to have } \\
\text { surgeons talking to surgeons and actually selling it prior to implementing it. It was supposed to have } \\
\text { been implemented by the surgeons. (P4-Nurse Manager) } \\
\text { The people who are trying to impose it are quite often not surgeons, and so they have their way, } \\
\text { and they would like to impose their way. (P6-Physician) } \\
\text { It was difficult because there was no education of the surgeons before hand. If you want to bring in } \\
\text { something you need to have education, and that is what we didn't have. (P3-Physician) } \\
\text { They do not operate in all the same way, and in fact innovation doesn't come out of standardization. } \\
\text { It comes out of innovation. Policies evolve differently among people because some will always be } \\
\text { better than others which are lagging behind perhaps. (P5-Nurse Manager) }\end{array}$ \\
\hline $\begin{array}{l}\text { Hierarchical team } \\
\text { culture and tribal } \\
\text { affiliations of members }\end{array}$ & $\begin{array}{l}\text { Comprised components of team culture } \\
\text { that influenced acceptance and use of } \\
\text { 'time out.' Interdisciplinary 'tribal' } \\
\text { affiliations, history, and communication } \\
\text { limited team cohesion, and consequently } \\
\text { influenced protocol fidelity. }\end{array}$ & $\begin{array}{l}\text { It is very hierarchical. One surgeon told me quite vehemently he doesn't like the stewardess telling } \\
\text { the pilot how to fly the plane. (P12-Registered Nurse) } \\
\text { We often talk about being one team, but it is in itself three teams. The surgeons don't see } \\
\text { themselves as part of the team; they see the others forming the team, but they invite in so to } \\
\text { speak. (P5-Nurse Manager) } \\
\text { With the older surgeons, this is a new thing, but certainly the younger ones coming through, they } \\
\text { are getting used to doing 'time out' and having that checklist where they have verified that it is the } \\
\text { correct site. (P8-Physician) } \\
\text { You will finally get a registrar, and you say to them 'can you do the final check?' and you can ask } \\
\text { them three times and they say 'I have done it' - all they have done is signed the form to say it has } \\
\text { been done, but they haven't actually verbally checked it with anybody. They see that as compliance; } \\
\text { they have put their signature to it-that is it. (P15-Registered Nurse) }\end{array}$ \\
\hline $\begin{array}{l}\text { Clashing clinical } \\
\text { priorities make it } \\
\text { difficult to incorporate } \\
\text { 'time out' into } \\
\text { practice }\end{array}$ & $\begin{array}{l}\text { Encompassed organisational factors that } \\
\text { influenced the extent to which 'time out' } \\
\text { was used. Heavy workloads and staff } \\
\text { shortages often constrained team } \\
\text { members' ability to perform the } \\
\text { final check. }\end{array}$ & $\begin{array}{l}\text { A lack of time. People just want to get the patient on the table and get started. The anaesthetist } \\
\text { wants to bring the patient in, and the surgeons aren't always available; they are not always here yet. } \\
\text { (P1-Registered Nurse) } \\
\text { With all these extra things on the satellite, the count, equipment, opening up, maintaining sterile } \\
\text { fields; your focus is off the patient. It is becoming a lot more difficult to maintain all the regulatory } \\
\text { things and have efficiency and turnaround. What you end up having is stressed staff doing a half } \\
\text { job on each of these things. (P3-Nurse Manager) } \\
\text { So, even though there is steps that we all do, and we all know we should be doing them, they don't } \\
\text { get done some times because we have different priorities. Like the surgeon's excuse was that he } \\
\text { had to look over these x-rays, and I guess that is a more important part of the operation, knowing } \\
\text { where he is going to operate and go in and how he is going to go about it. (P11-Registered Nurse) } \\
\text { If we had appropriate staff members, we could implement 'time out' 100\%, but until that time, there } \\
\text { is too much going on in theatre at the most crucial time which is the start. It is difficult when you } \\
\text { only have skeleton staff. (P4-Nurse Manager) }\end{array}$ \\
\hline
\end{tabular}

problems, nurses often initiated 'time out' when the physicians would not. This occurred despite the stipulation that it be instigated by the physicians when the 'time out' protocol was first introduced. 'Time out' was occasionally performed by nursing staff at a time not suited to the physician, and contributed to resistance to the check being done at all. These actions culminated in interdisciplinary dissension, 'time out' being performed inconsistently, a 'silo' mentality, miscommunication and compromised patient safety.

The third subcategory, clashing clinical priorities make it difficult to incorporate 'time out' into practice, was intensified by intervening conditions such as departmental culture and the amount of clinical experience participants possessed. Contextual conditions, such as conflicting priorities, staff shortages, increased workloads and inexperienced staff, contributed to 'time out' being used inconsistently. A tenuous balance existed between the imperative to perform 'time out' during the most demanding preparatory period when there was a multitude of tasks to perform-all of which had equal priority. Departmental expectations to 'maintain efficiencies and patient turnaround' were perceived as unrealistic because of nursing staff shortages. Attempts by nurses to manage these problems were evident in 'time out' being performed inconsistently or not at all. Consequently, nursing staff stress levels increased, and patient safety was compromised.

Table 2 defines each subcategory and provides quotes from participants.

\section{DISCUSSION}

Our findings suggest that surgical teams' willingness to use 'time out' was influenced by the complex interplay of organisational, departmental and individual factors. For instance, at the organ- isational level, the identified lack of leadership meant that key enablers were not included or even consulted vis-à-vis the implementation of the 'timeout' policy. Organisational implementation of 'timeout' needs to be owned and driven by senior physicians - rather than by senior nurses, as was the case in this particular organisation. Conceivably, garnering physicians' support by actively involving them in the process of policy design prior to its implementation may have contributed to ensuring the sustained adoption of 'time out' among physicians. A wholeof-organisation approach and the emergence of credible 'opinion leaders' who are seen as influential in effecting changes in clinical practice serve to inform quality in healthcare. ${ }^{14}$ In planning such an initiative, there must be an understanding of the subculture of a clinical service, and physicians who are willing to champion the change need to be included.

Sentinel events are very rare, and the suggestion of committing errors is abhorrent, given that the culture of surgery dictates that physicians must display control and certitude. ${ }^{16}$ The culture of surgery is reinforced by a medical model, which lauds autonomy and individualism, and proposes that error may be reduced by similar values of 'heroic endeavour.'17 Our findings concur with previous research which described the complexity of introducing prebriefing strategies into clinical practice because interdisciplinary communication is imbued by conflicting professional identities of members. ${ }^{5}$ Team members' different role foci influence what is communicated and when, and to whom it is communicated. Interestingly, this study has also identified that responsibility for performing 'timeout' was ostensibly devolved to nursing staff who were compelled to complete the check-albeit sans physician representation. Plausibly, such situations have the potential to set up conflict 
between physicians and nurses-and, in this study, contributed to sporadic usage among physicians.

Our findings have identified the impact of time pressures and workload on the team's ability to perform 'time out' - and still maintain patient safety. Significantly, the preoperative start-up period is the most crucial time because there are multiple procedures, all of which take precedence-a situation that heightens the risk of errors. In relation to the timing of 'timeout,' our study has emphasised the resultant tensions that nursing staff experienced due to competing priorities-that is, the need to prepare for a surgical case while concurrently concentrating on a crucial safety check. In some instances, as a result of time and personnel constraints, study participants performed 'timeout' inconsistently, or not at all. Clearly, if 'time out' is to be effective in reducing the potential for errors in $\mathrm{OR}$, then its guidelines must be followed. ${ }^{18}$ In Queensland public hospitals, there were 31 cases of procedures involving the wrong patient or body part reported during the period $2006 / 2007 .{ }^{18}$ In all instances, the 'time out' protocol was either not implemented or not appropriately applied. For 'time out' to be useful as a patient safety initiative, a shift in organisational culture is required to determine how such safety initiatives are managed at the clinical interface, ${ }^{16}$ with the view of redressing systems issues that contribute to increased workloads.

Our study has several limitations. First, it was conducted at one hospital site, which may be different from other Queensland public hospitals. Despite this, there was wide representation of participants which allowed diverse perspectives. Second, during the study period, the 'time out' policy was being reviewed within the organisation, and this may have influenced participants' perceptions. Finally, we have described inter-related factors that influence compliance not currently articulated in the literature with regard to who actually initiates 'timeout' and the associated pressures vis-à-vis its timing. However, there may be other factors not considered in this study.

\section{CONCLUSION}

Study findings have brought into sharper focus salient issues that must be considered within healthcare organisations when implementing patient safety strategies such as 'time out.' This study has advanced our understanding of the forces that lead to ambivalence, and consequently mitigate against compliance with 'time out' in clinical practice. Clearly, the challenges associated with achieving high compliance rates remain problematic despite 'timeout' being mandated in organisational policy. Research to explore the value of surgical time outs with associ- ated patient outcome, teamwork coordination and job satisfaction among surgical teams would be timely and useful.

Funding Research Centre for Clinical \& Community Practice Innovation, Griffith University.

\section{Competing interests None.}

Ethics approval Ethics approval was provided by the relevant hospital site and Griffith University.

Contributors All authors contributed to data analysis, the writing of this paper and critical revisions. BMG draughted and prepared the manuscript. Study design: BMG, WC, MW. Data collection: BMG. Data analysis: BMG, CF, WC, MW. Critical revision of manuscript: BMG, WC, MW, CF.

Provenance and peer review Not commissioned; externally peer reviewed.

\section{REFERENCES}

1. World Health Organization. 10 facts on safe surgery 2008, 2008. http://www.who int/features/factfiles/safe_surgery/en/index.html. [accessed 14 Aug 2008].

2. Kable AK, Gibberd RW, Spigelman AD. Adverse events in surgical patients in Australia. Int J Qual Health Care 2002;14:276-296. http://intqhc.oxfordjournals.org/ cgi/reprint/14/4/269. [accessed 14 Aug 2008].

3. Wilson I, Walker A. Theatre checklists and patient safety. Anaesthesia 2008;63:921-3.

4. Australian Institute of Health \& Welfare. Sentine/ events in Australian public hospitals 2004-05. Canberra: Australian Institute of Health \& Welfare, 2007.

5. Lingard L, Epsin S, Rubin B, et al. Getting teams to talk: development and pilot implementation of a checklist to promote interprofessional communication in the $\mathrm{OR}$. Qual Saf Health Care 2005;14:340-6.

6. World Health Organization. New checklist to help make surgery safer. Press release: New checklist to help make surgery safer. Geneva: World Health Organization, 2008.

7. Joint Commission Accreditation on Healthcare Organisations. Sentinel event statistics: October, 2007. Oakbrook Terrace: Joint Commission on Accreditation of Healthcare Organisations, 2007.

8. Makary M, Holzmueller C, Thompson D, et al. Operating room briefings: working from the same page. Jt Comm J Qual Patient Saf 2006;32:351-5.

9. DeFontes J, Surbida S. Preoperative safety briefing project. The Permanente 2004:8:21-7.

10. Dayton E, Henriksen K. Communication failure: basic components, contributing factors, and the call for structure. Jt Comm J Qual Patient Saf 2007;33:34-47.

11. Makary M, Holzmueller C, Sexton B, et al. Operating room debriefings. Jt Comm J Qual Patient Saf 2006;32:407-10.

12. Patton M. Qualitative research evaluation methods. 3rd edn. California: Sage, 2002.

13. Strauss A, Corbin J. Basics of qualitative research: Grounded theory procedures and techniques. Newbury Park: Sage, 1990.

14. Firth-Cozens J, Mowbray D. Leadership and the quality of care. Qual Saf Health Care 2001;10:3-7.

15. Thomson M, Oxman A, Haynes R, et al. Local opinion leaders to improve health professional practice and health care outcomes (Cochrane Review). Oxford: The Cochrane Library, 1999.

16. Schaefer R, Helmreich $R$, Scheidegger D. Safety in the operating theatre-Part 1: interpersonal relationships and team performance. Curr Anaesth Crit Care 1995;6:48-53.

17. Bleakley A. A common body of care: the ethics and politics of teamwork in the operating theatre are inseparable. J Med Philos 2006;31:305-22.

18. Patient Safety Centre. Analysis of procedures involving the wrong body patient or body part (2006/07). Brisbane: Queensland Health, 2008. 